\title{
Correction to: Impact of different post-harvest processing methods on the chemical compositions of peony root
}

\author{
Shu Zhu ${ }^{1} \cdot$ Aimi Shirakawa ${ }^{1} \cdot$ Yanhong Shi ${ }^{1} \cdot$ Xiaoli Yu$^{1} \cdot$ Takayuki Tamura $^{2} \cdot$ Naotoshi Shibahara $^{3} \cdot$ Kayo Yoshimatsu $^{4}$. \\ Katsuko Komatsu' ${ }^{1}$
}

Published online: 2 April 2019

(c) The Author(s) 2019

\section{Correction to: Journal of Natural Medicines (2018) 72:757-767 \\ https://doi.org/10.1007/s11418-018-1214-x}

The article Impact of different post-harvest processing methods on the chemical compositions of peony root, written by Shu Zhu, Aimi Shirakawa, Yanhong Shi, Xiaoli Yu, Takayuki Tamura, Naotoshi Shibahara, Kayo Yoshimatsu, Katsuko Komatsu, was originally published electronically on the publisher's internet portal (currently SpringerLink) on 13 April 2018 without open access.

With the author(s)' decision to opt for Open Choice the copyright of the article changed on 10 April 2019 to () The Author(s) [Year] and the article is forthwith distributed under the terms of the Creative Commons Attribution 4.0 International License (http://creativecommons.org/licenses/ by/4.0/), which permits use, duplication, adaptation, distribution and reproduction in any medium or format, as long as you give appropriate credit to the original author(s) and

The original article can be found online at https://doi.org/10.1007/ s11418-018-1214-x.

Shu Zhu

szhu@inm.u-toyama.ac.jp

Katsuko Komatsu

katsukok@inm.u-toyama.ac.jp

1 Division of Pharmacognosy, Department of Medicinal Resources, Institute of Natural Medicine, University of Toyama, 2630 Sugitani, Toyama 930-0194, Japan

2 Medicinal Plants Center, Toyama Prefectural Institute for Pharmaceutical Research, Kamiichi-Machi, Nakaniikawa-Gun, Toyama 930-0412, Japan

3 Division of Kampo Diagnostics, Institute of Natural Medicine, University of Toyama, 2630 Sugitani, Toyama 930-0194, Japan

4 Research Center for Medicinal Plant Resources, National Institutes of Biomedical Innovation, Health and Nutrition, 1-2 Hachimandai, Tsukuba, Ibaraki 305-0843, Japan the source, provide a link to the Creative Commons license and indicate if changes were made.

Open Access This article is distributed under the terms of the Creative Commons Attribution 4.0 International License (http://creativecommons.org/licenses/by/4.0/), which permits unrestricted use, distribution, and reproduction in any medium, provided you give appropriate credit to the original author(s) and the source, provide a link to the Creative Commons license, and indicate if changes were made.

The original article was corrected.

Publisher's Note Springer Nature remains neutral with regard to jurisdictional claims in published maps and institutional affiliations 